\begin{tabular}{|l|l|l|l|l|l|l|}
\hline InterteXto & Uberaba & UFTM & $\begin{array}{l}\text { v. 3 } \\
\text { n. } 2\end{array}$ & p. 107-128 & 2010 - jul. / dez. & ISSN 1981-0601 \\
\hline
\end{tabular}

\title{
CRONOTOPIAS ROMANESCAS: GERMINAL
}

Henri Mitterand ${ }^{1}$

O tempo e o espaço são duas categorias fundamentais do romance. Cada uma delas já foi objeto de múltiplos trabalhos. Gérard Genette propôs uma terminologia que se tornou clássica pelo estudo da temporalidade narrativa. Viu-se publicar, nos últimos anos, numerosas obras e artigos sobre os lugares romanescos. Porém, bem raras são as tentativas de apreendê-los juntos, nas suas conexões mútuas, o tempo e espaço. Dizer do mérito das análises de Mikhail Bakhtin sobre o cronotopo, ou seja, segundo seus próprios termos, sobre "aquilo que se traduz literalmente sobre o tempo-espaço: a correlação essencial das relações espaço-temporais, tais como foram assimiladas pela literatura."

As observações de Bakhtin, na maior parte antigas, cerca de cinqüenta anos, mas que conservaram todo o interesse, apresentam-se em ordem bastante dispersa. Os leitores de língua francesa podem achá-las por inteiro nas duas obras publicadas em francês das edições Gallimard: Esthétique et Théorie du roman e Esthétique de la création verbale. Bakhtin não se preocupa em sistematizar sua teoria, que subsiste heterogênea, espalhada em múltiplas definições e em múltiplos exemplos, usando de uma terminologia variável e fazendo alusão a uma classificação de gêneros e a uma teoria de dialogismo que se deve pesquisar mais além. Tudo isso não diminui sua importância: cada um deve somente tentar reconstruir a visão coerente que subentende essas páginas profundas e densas. É o que eu gostaria de fazer, antes de examinar a quais aplicações o conceito de cronotopo, em si, pode ser útil ao que concerne a obra romanesca de Zola, em particular, Germinal, depois, brevemente, refletir sobre os desenvolvimentos e os prolongamentos que permitiriam o cronotopo

\footnotetext{
${ }^{1}$ Universidade Paris III. Este foi publicado originalmente na revista Poétique, $\mathrm{n}^{\circ} 81$. Fevereiro, 1990. A tradução desse texto foi realizada por Clarissa Navarro Conceição Lima.
} 


\begin{tabular}{|l|l|l|l|l|l|l|}
\hline InterteXto & Uberaba & UFTM & $\begin{array}{l}\text { v. 3 } \\
\text { n. } 2\end{array}$ & p. 107-128 & 2010 - jul. / dez. & ISSN 1981-0601 \\
\hline
\end{tabular}

bakhtiniano de se integrar mais rigorosamente à semiótica narrativa, como o desejava o próprio Bakhtin.

\section{Os principais aspectos da cronotopia}

Inicialmente, tentemos esclarecer os principais aspectos do modelo cronotópico. Para isso é preciso acompanhar Bakhtin na sua extraordinária travessia de todas as literaturas e de todas as épocas, do romance grego ao romance russo, passando por Dante, Rabelais, Rousseau e Goethe. Zola não é citado, entretanto temos constantemente a impressão de que ele poderia ter sido, notadamente, quando, a propósito de Goethe, o crítico soviético utiliza, em termos próprios, a metáfora do grão que germina, tão próximo de um dos títulos primitivos de Germinal: "O mundo de Goethe é o grão que germina, real de parte em parte, visível na sua atualidade presente e tudo ao mesmo tempo embebido de um futuro igualmente real que crê nela." Convém, parece-me, distinguir de um lado os fundamentos do modelo, e de outro, seus níveis e suas formas.

\section{Os fundamentos do modelo}

\section{A indissolubilidade do tempo e do espaço}

A palavra cronotopo é um composto que, dentro de sua própria morfologia, testemunha, o que Bakhtin reconhece, a solidariedade indissolúvel do espaço e do tempo, no mundo real e na ficção romanesca. É a primeira orientação de base, aquela pela qual, de entrada de jogo, as taxonomias formalistas da narratologia se acham postas em questão. Bakhtin construía sua teoria no fim dos anos 20, sob influência imediata da física de Einstein. Mas deve-se, sem dúvida, remontar sua inspiração à Esthétique transcedantale de Kant, que me permitirá citar um pouco longamente:

\footnotetext{
${ }^{2}$ Esthétique de la création verbale. Paris: Gallimard, 1984, p. 257.
} 


\begin{tabular}{|l|l|l|l|l|l|l|}
\hline InterteXto & Uberaba & UFTM & $\begin{array}{l}\text { v. 3 } \\
\text { n. } 2\end{array}$ & p. 107-128 & 2010 - jul. / dez. & ISSN 1981-0601 \\
\hline
\end{tabular}

O tempo é a condição formal a priori de todos os fenômenos em geral. O espaço como forma pura de toda a intuição externa, só serve de condição a priori aos fenômenos externos. Ao contrário, como todas as representações, que elas tenham ou não por objetos das coisas externas, fazendo parte sempre por elas mesmas, na qualidade de determinações de espírito, a um estado interior, e que esse estado interior, sempre submisso à condição formal de uma intuição interna, volta assim no tempo, o tempo é uma condição a priori de todos os fenômenos em geral, a condição imediata dos fenômenos internos, e, pela mesma, a condição imediata dos fenômenos externos. Se eu posso dizer a priori que todos os fenômenos estão dentro do espaço, e que eles são determinados a priori seguido de relações de espaço, eu posso dizer de uma maneira absolutamente geral do princípio do sentido interno que todos os fenômenos em geral, quer dizer, todos os objetos do sentido, estão dentro do tempo e que eles estão necessariamente submissos às relações do tempo. ${ }^{3}$

Essa conexão kantiniana do tempo e do espaço, achamo-na dentro de todas as formas bakhtinianas; por exemplo, e para citar somente uma, ainda a propósito de Goethe: "Na visão concreta, globalizante de Goethe, o espaço terrestre e a história humana são inseparáveis, é o que se transmitirá a obra, dando sua intensidade e sua materialidade ao tempo histórico, sua humanidade impregnada do pensamento sobre o espaço."

\section{A predominância do tempo}

E, como em Kant, a conexão não é exatamente recíproca, mas ela implica uma subordinação de espaço ao tempo: cronotopo, tempo-espaço e não espaço-tempo (que é a formula de Einstein). A teoria do cronotopo é uma teoria do tempo romanesco mais que o espaço romanesco. É preciso ter cautela com isso, e não se deixar enganar pelo adjetivo spatio-temporel que se encontra também nas traduções francesas de Bakhtin e que inverte a ordem da subordinação desses dois fatores. "Tudo, no universo de Goethe, escreve Bakhtin, é espaço-temporal, tudo é cronotopo autêntico." Melhor seria dizer:

${ }^{3}$ Emmanuel Kant. "Esthétique trasncedentale", Critique de la raison pure. Paris: GarnierFlammarion, p.92. 


\begin{tabular}{|l|l|l|l|l|l|l|}
\hline InterteXto & Uberaba & UFTM & $\begin{array}{l}\text { v. 3 } \\
\text { n. } 2\end{array}$ & p. 107-128 & 2010 - jul. / dez. & ISSN 1981-0601 \\
\hline
\end{tabular}

chrono-spatial, forjando um neologismo. Por isso, Bakhtin faz glória a Goethe, é ter compreendido e mostrado que "as coisas estão no tempo e ao poder do tempo". Certamente, o tempo é "concretamente localizado dentro de um espaço", o "tempo do evento" liga-se indissoluvelmente "ao lugar concreto de sua realização"; mas é o tempo que dispõe da atividade criadora. É o tempo que dinamiza e dialetiza o espaço; e, dentro da narrativa, é o tempo que dinamiza a descrição tanto quanto a narração.

Assim, em Germinal, como em A Terra, o ritmo das estações domina o trabalho, a dor e as revoltas dos seres humanos; o espaço mineiro é o produto da história; e é a maturação da revolta, ao longo de um período trabalhado por todos os tipos de acontecimentos, que vai transformar, momentaneamente, o modo de ocupação dos espaços de Montsou, à superfície do solo e ao fundo das galerias. "O tempo, escreve Bakhtin, condensa-se, torna-se compacto, visível pela arte, enquanto que o espaço se intensifica, perde-se no movimento do tempo, do assunto, da História." Corrijamos imediatamente isso, sublinhando o caráter dialético da reflexão bakhtiniana: é bem claro que o "poder produtivo-criativo" do tempo se mede somente pelas transformações dos lugares, ou pelas migrações de um lugar para o outro. Toda revolução se realiza por meio de uma transgressão de fronteiras topográficas. E a história de uma sociedade é evidentemente determinada pelos recursos de seu solo, ou pelas formas de seu território. Taine, aqui, não estaria muito longe.

\section{Tempo histórico e tempo cíclico}

Terceiro ponto: o cronotopo favorito de Bakhtin é evidentemente aquele da história. História dos modos de vida, dos costumes, das instituições, das sociedades. Bakhtin opõe o tempo histórico, aquele dos "desígnios mais complexos do homem, das gerações, das épocas, dos povos, dos grupos

\footnotetext{
${ }^{4}$ Esthétique et Théorie du roman. Paris: Gallimard, 1978, p. 237.
} 


\begin{tabular}{|l|l|l|l|l|l|l|}
\hline InterteXto & Uberaba & UFTM & $\begin{array}{l}\text { v. 3 } \\
\text { n. } 2\end{array}$ & p. 107-128 & 2010 - jul. / dez. & ISSN 1981-0601 \\
\hline
\end{tabular}

sociais, das classes sociais [...], das contradições socioeconômicas" ${ }^{5 ",}$ e o tempo cíclico, aquele que "revela-se antes de tudo na natureza" e que articula os momentos da vida e das atividades do homem: a alternância de estações, o "crescimento das árvores, do gado, das idades do homem.". É ao tempo histórico, ao tempo externo, que concede em toda a sua obra a maior atenção, e é da lucidez na "visão e na representação do tempo histórico" que ele toma como comparação para seus julgamentos estéticos. O tempo interno, aquele da sucessão e da ordem dos acontecimentos da ação, não o retém muito.

\section{O cronotopo e os valores}

Finalmente, e esta será minha quarta observação preliminar, este subsídio de acordo com a historicidade do tempo da natureza e da vida liga Bakhtin à tradição do materialismo histórico, do marxismo para tudo dizer, e explica a distância que é colocada em respeito aos formalistas. Ela o conduz a misturar seu próprio discurso histórico a um discurso de valor e de norma, que é difícil saber se ele é totalmente assumido ou se ele é somente uma concessão ao sistema dogmático ao seio daquele que trabalhava. Eu serei tentado a crer sinceramente, tanto parece coerente o jogo de referências ideológicas implícitas ou explícitas que o conduz de Kant a Marx, passando por Hegel. A cada uma das três etapas aparece a consciência afirmada da necessidade. Necessidade filosófica, de tonalidade hegeliana, que, escreve ele acerca de Goethe, "penetra o tempo, que junta o tempo ao espaço e os tempos entre eles. ${ }^{8 "}$. Necessidade histórica, de tonalidade marxista, esta que releva as contradições, que conduz inevitavelmente à destruição das antigas hierarquias e das antigas convenções, que "abre necessariamente uma janela ao tempo futuro", que abre a "possibilidade de vir a ser, do crescimento, da

\footnotetext{
${ }^{5}$ Esthétique de la création verbale, p. 232.

${ }^{6}$ Ibid.

${ }^{7}$ Ibid., p. 233.

8 Ibid., p. 248.

${ }^{9}$ Ibid., p. 233.
} 


\begin{tabular}{|l|l|l|l|l|l|l|}
\hline InterteXto & Uberaba & UFTM & $\begin{array}{l}\text { v. 3 } \\
\text { n. } 2\end{array}$ & p. 107-128 & 2010 - jul. / dez. & ISSN 1981-0601 \\
\hline
\end{tabular}

transformação ${ }^{10 ", ~ e ~ q u e ~ c o n c e d e ~ a ̀ ~ c i v i l i z a c ̧ a ̃ o, ~ o ~ m o m e n t o ~ v i n d o, ~ s e u s ~ n o v o s ~}$ cronotopos.

A consciência da necessidade, e da dialética histórica, confunde-se então com o dever do artista. Nós encontramos novamente em Bakhtin, como em toda estética e crítica marxista da primeira metade deste século, a idéia de um progresso contínuo da representação romanesca, através da diversificação dos gêneros do romance. Os grandes narradores são aqueles que, como Rabelais e Goethe, tenham se dado conta do movimento da história na sua relação com as transformações do espaço terrestre. A tese culmina com a substituição declarada da modalidade do dever-fazer pela simples constatação do existente.

\begin{abstract}
A grande forma épica (a grande epopéia), que compreende também o romance, deve adquirir uma imagem geral do mundo e da vida, deve refletir o mundo e a vida por inteiro. O romance deve dar a imagem global do mundo e da vida sob o ângulo de uma época em sua integridade. É preciso que os acontecimentos representados no romance, de uma maneira ou de outra, substituam toda uma vida de uma época. É nesta atitude, para fornecer um substituto a toda realidade, que reside sua substancialidade artística. Os graus desta substancialidade e, conseqüentemente, de uma significação artística variam consideravelmente segundo os romances que caracterizam pelo grau de penetração realista em torno da realidade que procede a substancialidade que toma forma no romance inteiro. ${ }^{11}$
\end{abstract}

\title{
Os níveis e as formas do cronotopo
}

A elaboração do modelo cronotópico é, portanto o coração do pensamento estético e crítico de Bakhtin. Esse modelo representa sem dúvida a contribuição mais nova, mais viva, mais produtiva desse século à tradição estética hegelo-marxista. Sua exploração pode vivificar a semiótica e mais extensivamente a poética romanesca, mais longe que este espaço ideológico.

\footnotetext{
${ }^{10}$ Ver também Esthétique et Théorie du roman, op. cit., p. 350.

${ }^{11}$ Esthétique de la création verbale, op. cit., p. 249.
} 


\begin{tabular}{|l|l|l|l|l|l|l|}
\hline InterteXto & Uberaba & UFTM & $\begin{array}{l}\text { v. 3 } \\
\text { n. } 2\end{array}$ & p. 107-128 & 2010 - jul. / dez. & ISSN 1981-0601 \\
\hline
\end{tabular}

Convém agora esclarecer as hierarquias internas, os níveis e as formas, apesar da polissemia do termo cronotopo, nas nossas duas obras de referência, para chegarmos a uma possível classificação.

\section{O cronotopo cultural}

No seu emprego mais geral, cronotopo designa todo o universo humano determinado consubstancialmente por uma época e um lugar, e também toda visão, toda representação homogênea de um tal universo, todo quadro do mundo integrando a compreensão de uma época e de um cosmos. É nesse sentido que Bakhtin pode dizer de Roma que ela é "o grande cronotopo da história humana", ou que o mundo espaço-temporal de Rabelais é "o cosmos novamente descoberto à época da Renascença", um universo de espaço e de tempo que o homem pode e deve doravante conquistar:

Rabelais parece revelar aos nossos olhos o cronotopo da existência humana, ilimitada e universal. Eis aqui quem estava em perfeita harmonia com a época das grandes descobertas geográficas e cosmológicas que aproximava. ${ }^{12}$

\section{$O$ cronotopo de gênero}

Em uma segunda acepção, já mais circunscrita no vocabulário estético literário, o cronotopo é o traço determinante de um gênero, do ponto de vista de seu tratamento do tempo, primordialmente, e, secundariamente, do espaço. Aprofundamos aqui a teoria dos gêneros: o drama e a epopéia se inscrevem no tempo mitológico, enquanto que o idílio se constrói sob uma cronotopia cíclica, combinando os ciclos estacionais da natureza e o tempo convencional, familiar, da vida pastoral ${ }^{13}$, e que finalmente no romance "o espaço torna-se concreto e saturado de um tempo mais substancial, cheio de um senso real da vida

\footnotetext{
${ }^{12}$ Esthétique et Théorie du roman, op. cit., p. 383.

${ }^{13}$ Ibid., p. 254.
} 


\begin{tabular}{|l|l|l|l|l|l|l|}
\hline InterteXto & Uberaba & UFTM & $\begin{array}{l}\text { v. 3 } \\
\text { n. } 2\end{array}$ & p. 107-128 & 2010 - jul. / dez. & ISSN 1981-0601 \\
\hline
\end{tabular}

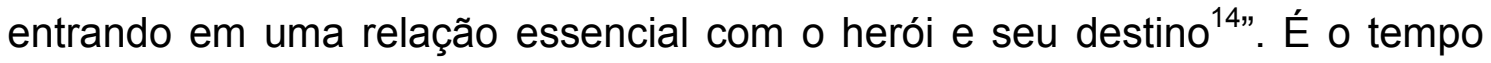
histórico, ou ainda o tempo dos costumes.

\section{O cronotopo de sub-gênero, ou de espécie}

Em um terceiro nível de especificidade, o cronotopo torna-se o princípio gerador e organizador de uma classe de obras dentro de um gênero dado. Princípio dual, além de que, compreendendo um traço temporal e um traço espacial. Assim, o romance grego associa o tempo das aventuras e o espaço de regiões estrangeiras - mas estrangeiras de maneira abstrata. O romance de cavalaria tem por "cronotopo original" o "mundo de maravilhas no tempo da aventura $^{15 " .}$ O romance picaresco atira seus heróis sobre a "grande vereda do mundo familiar".

Desta maneira o cronotopo, principal materialização do tempo no espaço, aparece como o centro da concretização figurativa, como a encarnação do romance inteiro. Todos os elementos abstratos do romance - generalizações filosóficas e sociais, idéias, análise das causas e dos efeitos, e assim de súbito gravitam em torno do cronotopo, e, por seu intermediário, colocam desejo e sangue, e participam do caráter imaginativo da arte literária. ${ }^{16}$

\section{O cronotopo da obra}

Ele resulta que cada obra romanesca singular - e é o quarto nível de determinação do conceito de cronotopo - apresenta uma variante combinatória dos traços cronotópicos de gêneros e de sub-gêneros. Os cronotopos entram em inserção para definir a fórmula cronotópica de uma obra:

Em Dom Quixote, por exemplo, o nó paródico do cronotopo do mundo estrangeiro e maravilhoso dos romances de cavalaria com a grande vereda do mundo familiar do romance picaresco

\footnotetext{
${ }^{14}$ Ibid., p. 269.

${ }^{15}$ Ibid., p. 300.

${ }^{16}$ Ibid., p. 391.
} 


\begin{tabular}{|l|l|l|l|l|l|l|}
\hline InterteXto & Uberaba & UFTM & $\begin{array}{l}\text { v. 3 } \\
\text { n. } 2\end{array}$ & p. 107-128 & 2010 - jul. / dez. & ISSN 1981-0601 \\
\hline
\end{tabular}

\section{é bem característica. ${ }^{17}$}

Um gênero como o idílio pode emprestar aos outros alguns de seus motivos cronotópicos: Bakhtin constata a influência do idílio sobre o romance sentimental à maneira de Rousseau, sobre o romance familiar, sobre o romance regionalista. É o grande dialogismo dos cronotopos.

\section{O cronotopo temático}

Nós trouxemos até aqui nossa atenção para o nosso próprio itinerário através dos escritos de Bakhtin dos cronotopos tipológicos, caracterizando as estruturas profundas da narrativa romanesca. Mas ainda, por um tipo de separação polissêmica, aparece sob esse mesmo termo uma série de motivos ou de temas espaço-temporais que revelam de preferência, ao meu juízo, as estruturas superficiais: tipos de cronotopos ao mesmo tempo celulares e tematizados, figurações temáticas de superfícies tais que a vereda, o castelo ou os cavaletes, definidos pelo próprio Bakhtin como os "temas isolados que entram como elementos constituintes nos assuntos de romances ${ }^{18 "}$ Bakhtin não se preocupa em especificá-los, e ele não teme em chamá-los de cronotopo tanto bem quanto o motivo situacional do reencontro (com todos seus entornos anteriores e ulteriores: a separação, a procura, a descoberta, o reconhecimento, etc., e seus valores afetivos, eufóricos ou disfóricos) que os motivos puramente locais da estrada, do salão burguês - cronotopo característico do romance Balzaquiano - ou do castelo - cronotopo dos romances de cavalaria. Mas o motivo da estrada, em particular, lhe permite construir uma brilhante demonstração do romance grego, e de levar por conseqüência do cronotopo temático até o cronotopo estrutural. Ele mostra em efeito que o cronotopo da estrada induzido todo um sistema de pressupostos, que fornece ao romance de aventuras sua estrutura específica: a estrada se concebe somente como lugar de itinerário, com suas peripécias e seus

\footnotetext{
17 Ibid., p. 310.

18 Ibid., p. 248.
} 


\begin{tabular}{|l|l|l|l|l|l|l|}
\hline InterteXto & Uberaba & UFTM & $\begin{array}{l}\text { v. 3 } \\
\text { n. } 2\end{array}$ & p. 107-128 & 2010 - jul. / dez. & ISSN 1981-0601 \\
\hline
\end{tabular}

reencontros, seu programa pré-construído de percursos, de obstáculos, de provas, de vitórias ou de fracassos sobre o tempo e sobre a distância. "A importância do cronotopo da estrada, pode assim indicar Bakhtin, é enorme dentro da literatura, raras são as obras que se passam sem algumas dessas variantes, e muitas dentre elas são diretamente construídas sobre ele. ${ }^{19 "}$ Nós as retomaremos.

\section{O cronotopo aspectual}

Reflexão feita, resta talvez um sexto emprego da noção de cronotopo: aquele que a faz uma espécie de categoria qualitativa ou modal da representação de um mundo, tal como é entendido, a distância (categoria à dominante espacial) ou o crescimento (categoria à dominante temporal). Próprio de Rabelais, aos olhos de Bakhtin, é ter construído seu mundo fictício sobre a antinomia da extensão e do crescimento, de um lado, e de enfraquecimento e degeneração, de outro. Tudo o que é precioso, qualitativamente positivo - o alimento, a bebida, a saúde, a bondade -, deve se estender o mais longe possível; tudo o que é negativo - a doença, a antiphysis, a corrupção, o mal, a maledicência, a mentira - deve perecer. Assim "a categoria do crescimento, do crescimento verdadeiro, espaço-temporal, é uma das categorias fundamentais do mundo de Rabelais. ${ }^{20 "}$

\section{Uma ilustração do cronotopo}

Medimos a riqueza e a complexidade desse material teórico e terminológico. Do cronotopo, articulação fundamental do entendimento humano, até o cronotopo tematizado em situações e em lugares definidos, passando pelo cronotopo cultural e pelo cronotopo composicional, a gradação é perspicaz - e minha classificação se arrisca a forçar os ângulos. A questão é saber se, como tal, o conjunto forma um modelo de textos romanescos, além

\footnotetext{
19 Ibid., p. 249.

20 Ibid., p. 314.
} 


\begin{tabular}{|l|l|l|l|l|l|l|}
\hline InterteXto & Uberaba & UFTM & $\begin{array}{l}\text { v. 3 } \\
\text { n. } 2\end{array}$ & p. 107-128 & 2010 - jul. / dez. & ISSN 1981-0601 \\
\hline
\end{tabular}

dos exemplos estudados por Bakhtin. Eu estaria tentado a responder que sim sob condições. Tentemos a título experimental, de investigar os "valores cronotópicos $^{21 "}$ de Germinal. Eu me surpreendo que Bakhtin faça silêncio sobre esse romance, justamente, sendo que a categoria cronotópica do crescimento, da germinação, é a seus olhos critério de qualificação estética. A via é portanto longamente nítida para a análise.

\section{Para historiar o estudo da cronotopia}

É preciso bem dizer, entre parênteses, que a cronotopicidade - mesmo sem a palavra - é o coração da reflexão sobre a estética romanesca, durante todo o século XIX. Não façamos de Bakhtin um começo absoluto. Todos os grandes romancistas apreenderam intuitivamente a solidariedade do espaço e do tempo, eles foram simbolicamente representados (quer o sonhamos ao espelho de Stendhal que passeia por um longo caminho, ou ao desdobramento do monstro à forma de crustáceo que, ao começo da História dos treze, de Balzac, figura o espaço parisiense à hora se seu despertar), e comentados: a Correspondência de Flaubert é preenchida de observações e de interrogações sobre o difícil amálgama dos momentos e dos lugares, as durações e os entendimentos. Estamos longe de ter esgotado o inventário e o estudo da reflexão dos romancistas do século XIX e do século XX sobre essa parte essencial de seus trabalhos. Os próprios títulos de suas principais obras Ilusões perdidas, Educação Sentimental, Germinal, Em busca do tempo perdido, Viagem ao final da noite, A condição humana, a Semana santa, formam juntos um metadiscurso ininterrupto sobre o espaço-tempo do romance. Esses títulos são em si cronotópicos.

\section{Cronotopos de Germinal}

${ }^{21}$ Ibid., p. 384. 


\begin{tabular}{|l|l|l|l|l|l|l|}
\hline InterteXto & Uberaba & UFTM & $\begin{array}{l}\text { v. 3 } \\
\text { n. } 2\end{array}$ & p. 107-128 & 2010 - jul. / dez. & ISSN 1981-0601 \\
\hline
\end{tabular}

Voltemos então, para Germinal, em sentido inverso do caminho seguido anteriormente, e remontemos aos motivos espaço-temporais tematizados até as grandes articulações composicionais e ideológicas.

\section{Os motivos}

$\mathrm{Na}$ planície limpa, numa noite sem estrelas, de uma obscuridade e de uma camada de tinta, um homem seguia sozinho a grande vereda de Marchiennes à Montsou, dez quilômetros de pavimento indo em frente, através dos campos de beterrabas.

Essas primeiras linhas de Germinal podem a elas somente servir de ilustração às demonstrações de Bakhtin sobre o cronotopo da estrada. Toda estrada romanesca não é necessariamente um cronotopo, eu suponho. Mas essa estrada pela qual Lantier chega à cena dos seus futuros combates me parece ocultar várias marcas da cronotopia. Inicialmente porque ela é a via de acesso ao espaço geral da ação, e que, sistematicamente, quando Étienne Lantier, seu papel exaustivo, parte, desiste do teatro do trabalho industrial e das lutas operárias, ele retomará a estrada, dessa vez em direção a Paris. Germinal é sob essa consideração o romance de uma travessia ou, se preferirmos, de uma etapa. Etapa na vida de um homem, etapa no destino de uma classe social, etapa na história de uma nação. Essa estrada pela qual surge Lantier, e ao longo da qual ele pára por algumas estações, é multiplamente investido pelo tempo, e portadora de múltiplos sinais e valores do tempo: o tempo biográfico, o tempo histórico, e também o tempo cíclico, associados e dando sentido um ao outro.

Cronotópica, a estrada, em Germinal, é por muitas outras razões. Ela é o vetor da busca - o operário sem trabalho teve de pegar a estrada para procurar uma nova possibilidade de trabalho -, o lugar do encontro iniciativo - aquele do velho Bonnemort -, a linha de comunicação imposta que une o espaço privado 


\begin{tabular}{|l|l|l|l|l|l|l|}
\hline InterteXto & Uberaba & UFTM & $\begin{array}{l}\text { v. 3 } \\
\text { n. } 2\end{array}$ & p. 107-128 & 2010 - jul. / dez. & ISSN 1981-0601 \\
\hline
\end{tabular}

do $\operatorname{coron}^{22}$ e espaço do trabalho, o depósito da mina, e cujos quilômetros ritmam as idas e vindas dos mineiros tão bem como o curso do tempo quotidiano. Ela circunscreve o espaço da festa, o espaço do jogo, o espaço do amor, com os casais entrevistos ao longo dos caminhos. Ela oferece finalmente aos mineiros escapados de suas galerias o espaço subitamente ilimitado da liberação e da anarquia: "E a banda, pela planície rasa, toda branca de gelo sob o pálido sol de inverno, partia, superlotava a estrada, através dos campos de beterraba." É a estrada da ruptura instintiva e massiva, é o novo cronotopo de uma violência popular de massa, cega e aqui mesmo frágil. Mas cuja força aqui sente e descreve pela primeira vez, profetiza as grandes revoltas revolucionárias do século $\mathrm{XX}$. Sim, uma noite, o povo, abandonado, desenfreado, galopava
sobre os caminhos [...]. Sim, seriam os mesmos trapos, o
mesmo trovão de grossos tamancos, a mesma multidão
medonha, de pele suja, de hálito fétido, varrendo o velho
mundo, sob seus manifestos transbordados de bárbaros [...]
Sim, eram essas coisas que passavam pela estrada, como
uma força da natureza, e eles recebiam o vento terrível na
face.

Essa estrada é a tal pela qual um dia próximo aparecerão repentinamente os bárbaros, pela destruição do velho mundo. "Antecipai-vos de serem justos, adverti Zola. Senão, a terra se abrirá."

Sim, a terra se abrirá. É o que existe em Germinal, um outro tempoespaço singular, e característico, na singularidade, de uma nova idade social. Pensamos evidentemente na mina, variante de um cronotopo mais extenso, comum ao imaginário de Zola e à literatura romântica: o cronotopo do lugar subterrâneo, que é ao mesmo tempo inferno e sepultura, encarceramento e maldição, espaço privado de luz e de saída, que a história reserva aos infelizes e aos oprimidos, mas de onde podem surgir cataclismas tanto mais violentos quanto eles foram longamente contidos. Espaço e duração de toda uma outra

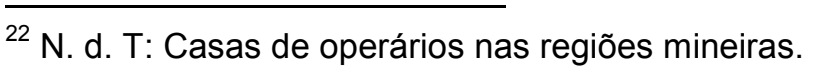




\begin{tabular}{|l|l|l|l|l|l|l|}
\hline InterteXto & Uberaba & UFTM & $\begin{array}{l}\text { v. 3 } \\
\text { n. } 2\end{array}$ & p. 107-128 & 2010 - jul. / dez. & ISSN 1981-0601 \\
\hline
\end{tabular}

natureza que o espaço e a duração da superfície terrestre e do grande dia. Ele se vai assim, para pegar outros exemplos, do esgoto dos Miseráveis, ou do longo corredor carcerário daquele que os guardas da rainha da Inglaterra conduzem Gwynplaine, no Homem que ri. São as prisões de Piranèse. O espaço aqui é estrangulado, sufocante e misterioso, com as saídas decepcionantes, de portas abrindo somente sobre barras, muralhas, uma arquitetura acentuada, ilusória, subindo ou mergulhando em todos os sentidos, um tipo de oclusão vertiginosa. Somente podemos progredir lentamente, e na disforia da cegueira e da sufocação, em um permanente infortúnio do corpo e do espírito. Nós apoiamos ou nós escorregamos, nós perdemos o equilíbrio e também o sentido do tempo. Nós viajamos nas entranhas de um monstro: Hugo usa as palavras boyau ${ }^{23}$ e intestin ${ }^{24}$ enquanto que Zola evoca a digestão saciada de Voreux. Os corredores de $\mathrm{O}$ homem que ri e as galerias subterrâneas de Germinal partilham dos mesmos valores cronotópicos, ao mesmo tempo pela escolha de traços espaço-temporais, pela escolha de imagens e pela escolha de significações simbólicas. O ser se choca com a duração indiferente e opressiva da rocha, do universo mineral. E ao mesmo tempo, por curiosa equivalência metafórica que associa o mineral e o viscoso, ele é absorvido, engolido, digerido, como, diz o texto de Germinal, "uma ração de carne humana". A prisão é a mina, mesma realidade e mesmos fantasmas, de O Último dia de um condenado ao Homem que ri e à Germinal. Mesmo topos romântico, e mesmo cronotopo simbólico, significando a fragilidade do indivíduo enclausurado nos túneis da história, do horror e da aniquilação, de deglutição do homem pela instituição que se alimenta, de sua transformação excrementicial em mercadoria, em seguida em detrito, de seu escorregamento inelutável em direção ao horror e à morte. "Nada é temível, escreve Hugo, como as coisas obscuras as quais chegamos pelos declives insensíveis."

\footnotetext{
${ }^{23} \mathrm{Ndt}$ : intestino de animal.

${ }^{24} \mathrm{Ndt}$ : intestino de ser humano.
} 


\begin{tabular}{|l|l|l|l|l|l|l|}
\hline InterteXto & Uberaba & UFTM & $\begin{array}{l}\text { v. 3 } \\
\text { n. } 2\end{array}$ & p. 107-128 & 2010 - jul. / dez. & ISSN 1981-0601 \\
\hline
\end{tabular}

Nós o vemos, o intertexto do subterrâneo e o intertexto da estrada se respondem na imaginação romanesca do século XIX, e em particular em Hugo e em Zola. E estamos longe de ter esgotado traços comuns do cronotopo subterrâneo de Hugo e este de Zola que não são nulos a interpretar segundo o mesmo código. Pois eles se inserem dentro de grandes unidades cronotópicas fortemente diferentes.

\section{O percurso heróico}

Germinal é um perfeito exemplo de interseção dos cronotopos. Reconhecemos os elementos de um romance familiar, e mesmo de muitos romances familiares, com a parte que expõe os lugares e os momentos do ritual conjugal, paternal, filial, e aquelas do companheirismo: lugares e tempos do amor, do nascimento, da infância, da velhice, das reuniões familiares, das festas, dos desentendimentos e dos compromissos. Reconhecemos também os motivos estruturais do romance de aprendizagem e de iniciação, do romance biográfico, e mesmo do romance picaresco: Lantier faz sua carreira, morando provisoriamente em uma sociedade e próximo de tipos humanos que Ihe eram até lá desconhecidos ou mal conhecidos, e que o recolhem, o acolhem e o inserem. Germinal entra assim em uma tradição romanesca cujos artifícios literários, os modelos de composição são perfeitamente codificados. $O$ Vermelho e o Negro, Os Miseráveis, O Homem quem ri, Germinal, mas também Sem família, partilham, somam tudo, o que podemos chamar de mesmo "biocronotopo", o mesmo percurso de vida.

Mas Lantier, à diferença de Julien, de Jean Valjean, de Gwynplaine ou do jovem herói de Hector Malot, torna-se um condutor dos homens, um líder de uma ação coletiva. E isso basta para relativizar aqui a parte do tempo do idílio e aquela do tempo da biografia, isto basta para dar a Germinal uma estrutura e valores cronotópicos inéditos. Eu parafrasearia de bom grado Bakhtin evocando Goethe, escrevendo como ele: “Aqui, o processo de reeducação pessoal se mistura àquele da demolição e da reconstrução de toda a 


\begin{tabular}{|l|l|l|l|l|l|l|}
\hline InterteXto & Uberaba & UFTM & $\begin{array}{l}\text { v. 3 } \\
\text { n. } 2\end{array}$ & p. 107-128 & 2010 - jul. / dez. & ISSN 1981-0601 \\
\hline
\end{tabular}

sociedade, ou seja, ao processo histórico. ${ }^{25 "}$ Estando bem entendido que o processo histórico em questão é aquele que afeta a sociedade européia do fim do século XIX.

De fato, tudo, em Germinal, é determinado pelas fatalidades econômicas, pela escolha e pelos engajamentos sociais, e no fim das contas políticas. A primeira lição que Etienne Lantier recebe de Bonnemort é uma lição de história econômica e social. Cada um desses homens, dos quais ele escutará mais tarde a palavra, é agente de uma empresa política que procura transformar as relações de poder entre as classes, quer seja pela via reformista, com Rasseneur, ou pela via niilista, com Souvarine. A mina é representada em Germinal simultaneamente como um recurso vital de energia para a sociedade industrial e como o lugar onde os afrontamentos sociais se fazem mais agudos e mais brutais. O romance une um herói que é novo por seu estatuto social e político e um lugar que é típico da produção, da troca e do consumo modernos, em uma ação imitando as grandes fraturas que dilacera o corpo social, classe contra classe. O cronotopo de Germinal, na verdade, combina os chefes do romance familial, do romance de aprendizagem, do romance de aventuras, do romance histórico. Vemos entre parênteses que, a esse nível de análise, a palavra naturalista não significa grande coisa. Mas, além dessa combinação, o que importa, é uma intuição espaço-temporal totalmente original, que sintetiza a entrada da sociedade européia do século XIX em uma civilização nova, aquela da mina e da usina, e, consubstancialmente, aquela dos conflitos de classes. Poderíamos dizer, por consequência, para fazer pastiche de Bakhtin, que Germinal tem por cronotopo o tempo da luta de classes no mundo do capitalismo industrial. Os cronotopos tematizados da estrada e da mina tomam efeito, sentido e valores somente em função dessa estrutura cronotópica que os engloba e os determina.

${ }^{25}$ Ibid., p. 375. 


\begin{tabular}{|l|l|l|l|l|l|l|}
\hline InterteXto & Uberaba & UFTM & $\begin{array}{l}\text { v. 3 } \\
\text { n. } 2\end{array}$ & p. 107-128 & 2010 - jul. / dez. & ISSN 1981-0601 \\
\hline
\end{tabular}

Mas isso não seria suficiente ainda. $E$ é aqui que subitamente às vistas de Bakhtin, tão universais que sejam sua cultura, podem nos parecer limitadas ao excesso pelos pressupostos da estética marxista, que somente tem olhos para o realismo crítico. É aqui que o próprio conceito do cronotopo, tal que ele o explicita, coloca-se a produzir um som por muito monótono, desprovido dessas vibrações, dessas ressonâncias, dessas virtualidades heurísticas às quais reconhecemos a riqueza gerada de um perfeito instrumento analítico. Não que devêssemos a partir de então abandoná-lo. Era preciso ao contrário Ihe dar essas virtualidades, essa produtividade que lhe falta. Isso pode se realizar ao menos de duas maneiras.

\section{Reavaliação do cronotopo}

\section{A particularidade do mito germinaliano}

Inicialmente recusando a subjugar absolutamente as categorias e as escalas de medida histórico-sociológicas estabelecidas por Mikhaïl Bakhtin, mesmo se, num primeiro tempo, elas pareçam cômodas e se somos seduzidos pelas variações que elas autorizam sobre o romance grego, sobre Rabelais ou sobre Goethe. O caso de Germinal é significativo a esse olhar. Toda tentativa de reduzir sua cronotopia a um simples modo particular de relação entre o romance e a história, entre o real e sua representação, só pode ser mutiladora. Pois o tempo idílico e cíclico e o tempo biográfico e histórico, aqui longe de se distinguir, de se separar, de coexistir como água e óleo, se confundem e se conjuntam para dar nascimento a uma cronotopia que não é nem totalmente aquela do imaginário mítico, mas que participa dos dois ao mesmo tempo, como já o mostraram Jean Borie, David Baguley, Roger Ripoll, Auguste Dezalay ou Sandy Petrey. É nesse sentido que ao menos pelo que concerne Zola, sobre o qual, vimos, Bakhtin observa um silêncio prudente, a noção de cronotopo deve ser reavaliada. Zola transpõe a temporalidade da história e 


\begin{tabular}{|l|l|l|l|l|l|l|}
\hline InterteXto & Uberaba & UFTM & $\begin{array}{l}\text { v. 3 } \\
\text { n. } 2\end{array}$ & p. 107-128 & 2010 - jul. / dez. & ISSN 1981-0601 \\
\hline
\end{tabular}

uma temporalidade da natureza, ultrapassando assim a antinomia entre o acaso histórico e a necessidade biológica, entre a conjuntura e a eternidade.

A dinâmica dos movimentos humanos reúne na obra de Zola aquela das forças naturais. E, mesmo que Zola empreste à natureza os arrebatamentos e as loucuras da humanidade, ele descreve os fluxos e os refluxos das turbas em imagens de natureza. O povo em cólera é matilha, torrente, inundação. Imagens românticas, sem dúvida, mas que acompanha uma tomada de consciência historicamente inédita e que não encontramos, tal qual, nem em Balzac, nem em Hugo, nem em Michelet, nem em Flaubert: é claro que para Zola a emergência da turba, da massa humana, como energia autônoma, é destinada a modificar radicalmente o curso da história.

Entretanto, a turba perde as batalhas ante a instituição e suas defesas. A epopéia insurrecional termina em tragédia. A ordem estabelecida permanece não transgredível, e o povo impotente de sacudir as correntes do trabalho, da miséria e da obediência. A decepção é a medida das esperanças. Os homens e as mulheres do povo (Maheu como Silvère, la Mouquette como Miette) pagam de suas vidas o entusiasmo de suas ilusões. Se é verdade que as últimas linhas de Germinal fazem surgir "uma tropa, negra vingadora, que germina nos caminhos, engrandece pelas colheitas do século futuro, e cuja germinação explodiria logo mais a terra", a vitória e a felicidade do povo pertencem ainda à utopia. Observemos que essa temática alternada dos impulsos e dos fracassos populares estava em uma grande medida ditada a Zola pela história de seu século, que não tinha visto menos de quatro revoluções fracassadas: 1793, 1830, 1848, 1871.

O exemplo de Germinal mostra então que toda definição unívoca do cronotopo romanesco é insuficiente e inexato. É preciso evitar as fórmulas peremptórias que pretendem fechar numa única frase todo o espaço-tempo de uma obra que sobreviveu à sua própria contemporaneidade. O texto de Zola, sempre móvel, não pára jamais sobre uma imagem ou um sentido. Por isso Michel Serres vê uma metáfora global dessa circulação à catástrofe que é o 


\begin{tabular}{|l|l|l|l|l|l|l|}
\hline InterteXto & Uberaba & UFTM & $\begin{array}{l}\text { v. 3 } \\
\text { n. } 2\end{array}$ & p. 107-128 & 2010 - jul. / dez. & ISSN 1981-0601 \\
\hline
\end{tabular}

fundamento da termodinâmica, ciência chave do século XIX - por onde nós voltamos ao tempo-espaço de uma civilização do carvão e do vapor, mas ainda à circulação do sangue das árvores genealógicas, àquele do desejo entre os corpos e da natureza aos corpos, à circulação e à troca de bens, de ouro, de álcool, de mulheres, de signos... Tudo corre e se dissipa em Zola dentro de uma cronotopia da circulação generalizada, com seus fluxos e suas paradas, seus derramamentos, seus desmoronamentos ou suas exaustões, suas entropias também. Pois o grande motor universal é submisso à degradação da energia - e a revolução, ela própria, devora-se e exaure-se. Contrariamente ao que crê e proclama Bakhtin, e não importa o final postiço de Germinal, o futuro não está assegurado. De onde, talvez, a resolução final, no imaginário cronotópico de Zola, de uma intuição nova e profunda da dialética social na figura dominante, ela mesma cronotópica, do eterno retorno; de onde a fertilidade sempre observável da temporalidade circular do mito sobre essa, vetorizada, da história, como se o motor da vida, segundo as palavras de Auguste Dezalay, fosse somente um motor imóvel.

\section{Para uma semiotização do cronotopo}

Mas é tempo enfim de se distanciar um pouco do tematismo dentro do qual Bakhtin se enclausura e nos enclausura. $O$ tempo e o espaço são quase sempre evocados, nos seus trabalhos sobre o cronotopo, como substâncias referenciais da narrativa, jamais verdadeiramente como formas, como elementos funcionais da narrativa. Ora, se a noção do cronotopo tem um sentido e uma utilidade, é talvez, sobretudo em sua determinação narrativa, na sua inter-relação com os outros componentes do programa narrativo, ou seja, o sistema dos personagens e a lógica da ação. Eu não posso ir muito longe nessa direção. Eu coloco, somente como hipótese de pesquisa, no prolongamento do ensino de Bakhtin, que existe tantos cronotopos quanto personagens, e também que cada fase canônica da narrativa institui seu próprio cronotopo. O tempo-espaço de Lantier não é evidentemente idêntico ao 


\begin{tabular}{|l|l|l|l|l|l|l|}
\hline InterteXto & Uberaba & UFTM & $\begin{array}{l}\text { v. 3 } \\
\text { n. } 2\end{array}$ & p. 107-128 & 2010 - jul. / dez. & ISSN 1981-0601 \\
\hline
\end{tabular}

de Maheu. E o tempo-espaço da crise insurrecional não é aquela da maturação das revoltas e das aprendizagens. A noção do cronotopo merecia ser semiotizada ainda mais que ela não o é na Esthétique et Théorie du roman. É de resto uma etapa indispensável em direção ao estudo, retórico e estilístico, de maneira cujo tempo e espaço são conjuntamente verbalizados e tornados perceptíveis pelo leitor.

Algumas observações sobre esse ponto, para finalizar, e sempre a propósito da cronotopia de Germinal. O espaço de Notes sur Anzin, no dossiê preparatório de Germinal, é um espaço sem personagens, uma maneira geográfica de estar lá. O espaço de Germinal, do romance acabado, é desde as primeiras linhas o espaço de Étienne Lantier, o espaço de um ator e de uma ação, de uma fazer: isso muda tudo. O reencontro de Etienne Lantier e de Bonnemort funcionaliza o espaço de Anzin, vindo do espaço de Montsou, segundo uma necessidade dramática que não é da ordem da história, mas da ordem de uma história.

O romance estabelece uma ligação sobre a descrição de um espaço e de um tempo, mas para lhes impor suas próprias leis. O lugar romanesco é realizado imediatamente como um lugar de provas. Prova pragmática: é preciso vencer o cansaço, o medo do desconhecido, penetrar esse lugar estranho. Prova cognitiva: é preciso reconhecer os signos, dissipar a sensação agonizante da opacidade das coisas. A reparação espacial, focalizada pela personagem, é uma primeira performance e também uma maneira de apropriação: o espaço da mina torna-se a partir de então o espaço do herói.

Montsou não é então uma simples decoração, um simples espaço de referência geográfica e histórica. Cada um desses atributos topográficos faz o objeto de uma reescrita em código-romano e de uma modalização sobredeterminada pela matriz geral da narrativa. Do espaço contingente ou simplesmente possível nas primeiras linhas (Lantier teria podido não parar nesse lugar), ele tornou-se o espaço necessário. Do espaço misterioso, ele tornou-se o espaço do conhecimento e da certeza: é aqui que o herói sabe a 


\begin{tabular}{|l|l|l|l|l|l|l|}
\hline InterteXto & Uberaba & UFTM & $\begin{array}{l}\text { v. 3 } \\
\text { n. } 2\end{array}$ & p. 107-128 & 2010 - jul. / dez. & ISSN 1981-0601 \\
\hline
\end{tabular}

partir de então poder e dever encontrar o pão, o trabalho; e é aqui que se desenrolará o afrontamento simbólico deste monstro dos novos tempos, o Voreaux, pelo qual Lantier é já designado. Enfim, o espaço interditado, o espaço da mina tornou-se o espaço permitido, esperando vir a ser espaço obrigatório; pois o herói só poderá sair de duas maneiras, igualmente condenáveis ainda que ao olhar de duas leis diferentes: seja transgredindo os limites dispostos pela e para a segregação social (isso será a corrida sobre as estradas no entorno), seja abandonando seus companheiros de provas (isso será a partida final para Paris.)

O romance, então, não se explica dentro dos termos de uma cronotopia histórica, vê-se, preferencialmente, que se passa o inverso: é a atenção cronotópica inicial, tal como os documentos preparatórios conservam o traço, que acha sua chave no romance. É preciso que o espaço real de Anzin, identificável hic et nunc, cesse de ser percebido na linguagem da história e da geografia, já que ele deve aparecer como o teatro de uma luta operária que reencarna as antigas jacqueries ${ }^{26}$ e os antigos terrores, e, mais além, a revolta secular e sempre recorrente do escravo contra o dono. Não é de cronotopo, em resumo, que sempre já aparece modalizado e modelizado pelas formas da narrativa.

A teoria bakhtiniana do cronotopo é uma contribuição fundamental ao estudo dos componentes do romance, e mais além, ao estudo dos gêneros. Ela mostra o tempo da obra dentro do espaço e o espaço da obra dentro do tempo, solidariamente. Podemos e devemos derivar todos os tipos de aplicações, compreendidas na ordem da linguagem. Ela renova profundamente nossa reflexão sobre a relação do romance e da história, da literatura e da evolução das sociedades. Ela permite compreender porque um grande romance, como

${ }^{26}$ A Jacquerie ou revolta dos Jacques foi uma insurreição camponesa que teve lugar no Norte da França, entre 28 de maio e 24 de junho de 1358, durante a Guerra dos Cem Anos. (N. do T.) 


\begin{tabular}{|l|l|l|l|l|l|l|}
\hline InterteXto & Uberaba & UFTM & $\begin{array}{l}\text { v. 3 } \\
\text { n. } 2\end{array}$ & p. 107-128 & 2010 - jul. / dez. & ISSN 1981-0601 \\
\hline
\end{tabular}

Germinal, ou A educação sentimental, ou Os miseráveis, pode ser mais rico de saber, sobre "tudo da vida", que uma pura especulação filosófica ou uma enciclopédia histórica ou científica. Ela ajuda a análise literária a propor verdadeiras e grandes questões aos textos.

Mas é claro que ao cronotopo bakhtiniano falta a dupla dimensão do conteúdo simbólico e da forma semiótica. A relação que Bakhtin institui entre a obra e a história pelo meio do cronotopo é muito unilateral. Restaria sem dúvida agora mediatizá-la e afiná-la, tendo em conta não somente o tempoespaço dentro da obra, mas também do tempo-espaço da obra. 